\title{
Production of $\mathrm{OB} / \mathrm{GYN}$ physicians to reduce the deficit of maternity providers in Alabama
}

\author{
Daniel M Avery Jr*, Marion D Reed and John G Bell \\ College of Community Health Sciences, The University of Alabama, Tuscaloosa, AL, USA
}

\begin{abstract}
Background: Alabama has the second highest rate of infant mortality of any state in the United States. This high rate of infant mortality is related to closure of rural labor and delivery units, closure of rural hospitals, lack of access to obstetric care and lack of OB/GYN and family physicians obstetrics providers. Obstetrician/ gynecologists or family physicians trained in obstetrics are essential for hospitals to provide obstetrical care. This study was designed to determine if the production of obstetrician/gynecologists by the University of Alabama School of Medicine was comparable to other similar medical educational institutions.
\end{abstract}

Materials and Methods: A list of 6271 graduates of the University of Alabama School of Medicine from the Birmingham, Tuscaloosa and Huntsville campuses from 1974 to 2015 was obtained from the published records of the main campus in Birmingham. Variables included the years of matriculation and graduation, full names, specialty choice, name and location of PGY1 institution and name and location of residency.

Results: A total of 435 medical students assigned to the Birmingham, Tuscaloosa and Huntsville Campuses matched into OB/GYN from 1974 to 2015. Some 334 graduates practiced OB/GYN (84.9\%). Thirty graduates switched from other specialties into OB/GYN. Twenty-two graduates who matched into OB/GYN, changed specialties or the specialty was unknown. Among the graduates who matched into OB/GYN, 67 pursued fellowships and practiced subspecialties.

Conclusions: On average, $6.9 \%$ of medical students from the University of Alabama School of Medicine matched into OB/GYN compared to the national average of 5.9\% The production of obstetrician/gynecologists is consistent with the most recent data from the ACOG Workforce Study.

\section{Introduction}

Alabama has the second highest infant mortality rate in the United States $[1,2]$. This high infant mortality rate is related to closure of rural labor and delivery units, closure of rural hospitals, lack of access to obstetric care and lack of OB/GYN and family physician obstetrics providers [2]. Lawsuits, cost of malpractice insurance, lack of trust by the community, bad outcomes, insufficient numbers of specialized nursing staff, lack of 24-hour anesthesia coverage, lack of up to date technology necessary to meet the standard of care, low reimbursement, patients with no health insurance coverage and insufficient numbers of patients who want to deliver locally contribute to the loss of local obstetric services [2]. For these reasons, small, rural hospitals that struggle financially, often choose to discontinue labor and delivery services. The result of this is more out-of-hospital deliveries, more deliveries in transit, more deliveries at hospitals without obstetric services, longer travel times, and more preterm deliveries [2]. Obstetrician/gynecologists or family physicians trained in obstetrics are essential for hospitals to provide obstetrical care.

The greatest need for obstetrical care is in rural, underserved areas of this country [3]. According to Rayburn's frequently quoted 2012 article in Obstetrics and Gynecology, approximately half of U. S. Counties have no obstetrics provider, leaving some 10 million reproductive-aged women (aged 15 to 45 years) without care [4]. Unfortunately, many of these women live in rural, underserved communities [4]. Lack of obstetrics care and providers is associated with poor outcomes, poor access to care, more complications and more expensive care [5]. Most $\mathrm{OB} / \mathrm{GYN}$ residency graduates practice in larger, urban areas, rarely in rural communities. These factors contribute to a maldistribution of obstetric providers which could worsen [4].
The number of $\mathrm{OB} / \mathrm{GYN}$ residency programs in this country has decreased from 306 to 246 since 1993 with no immediate plans of developing new programs [6]. In the 1980's there were four OB/GYN residency programs in Alabama and now there are only two. There are currently 1200 PGY1 first year positions in OB/GYN [7]. Some $5.9 \%$ of U.S. medical school graduates match into OB/GYN [7]. The number of retiring obstetrician/gynecologists closely approximates the number of graduating OB/GYN residents [7]. There is a projected need for $6 \%$ more OB/GYN physicians by 2020 according to a study by Dall et al. [8]. This number translates to about 2090 more physicians [8]. There were 474 obstetrician/gynecologists serving slightly more than 2,000,000 women in Alabama in 2014 [9]. The female population is expected to increase by $6 \%$ by 2030 [9]. Half of Alabama's counties have no OB/ GYN [9]. Alabama is predominantly rural with the exception of 7-8 cities. More than $50 \%$ of births are funded by Medicaid [9]. The goal of this study was to examine the production of OB/GYN physicians from the graduates of the University of Alabama School of Medicine main and regional campuses.

\section{Materials and methods}

This project did not require approval by the Institutional Review Board of the University of Alabama because it did not involve human

${ }^{*}$ Correspondence to: Daniel M Avery, MD, Professor \& Former Chair of Obstetrics \& Gynecology, College of Community Health Sciences, The University of Alabama, Tuscaloosa, AL, USA, E-mail: davery@ua.edu

Received: September 17, 2018; Accepted: September 24, 2018; Published: September 26, 2018 
subjects. A list of 6271 graduates of the University of Alabama School of Medicine from the Birmingham, Tuscaloosa and Huntsville campuses from 1974 to 2015 was obtained from the published records of the main campus in Birmingham. Graduates assigned to the Montgomery campus were not included in this study because this campus opened in 2014. Variables included the years of matriculation and graduation, full names, specialty choice, name and location of PGY1 institution and name and location of residency.

Researchers expanded this database to include additional information found in Table 1. Information was obtained primarily from Google Search Engine. Publicly available data from internet sources was selected as the primary source of information with verification from other sources when feasible, recognizing the positives as well as the limitations of internet-based data. Information was obtained on 6238 (99.5\%) graduates assigned to the three campuses from 1974 to 2015. Physicians were identified by their practice website. The database was then configured into a SPSS database.

\section{Results}

Results of the study are found in Table 2. From 1974 to 2015, 435 medical students assigned to the Birmingham, Tuscaloosa and Huntsville Campuses matched into OB/GYN. Detailed information including practicing specialty and location of practice was obtained on all but two graduates. On average, $6.9 \%$ of medical students matched into OB/GYN compared to the national average of 5.9\% [6]. As of 2015, 42 graduates were still in residency training. A total of 30 graduates changed from other specialties into OB/GYN (Internal Medicine, Pediatrics, Family Medicine, Pathology, Transitional Year, General Surgery, Psychiatry, Preliminary Medicine and Preliminary Surgery). Among graduates who matched into OB/GYN, 22 changed specialties (Emergency Medicine, Internal Medicine, Ophthalmology, and Family Medicine) or their practice was unknown, Sixty-seven graduates pursued fellowship training and practiced OB/GYN subspecialties including Maternal Fetal Medicine, GYN Oncology, Reproductive Endocrinology and Infertility, Uro-gynecology and Pelvic Reconstructive Surgery. Ultimately, some 334 graduates practiced general OB/GYN (84.9\%). It is unknown how many practicing obstetrician/gynecologists are hospitalists, laborists, academicians, researchers or administrators.

\section{Conclusions}

The production of OB/GYN generalists and subspecialists are consistent with the most recent data from the ACOG Obstetrician/ Gynecologist Workforce Study in the United States from 2017 [6]. While the production of OB/GYN physicians is consistent with the national data, more OB/GYN physicians are needed to supply the projected need [7]. Physicians matching into OB/GYN often changed

Table 1. Expanded Database of the University of Alabama School of Medicine Graduates from the Tuscaloosa, Birmingham and Huntsville Campuses (1974-2015)

\begin{tabular}{|c|c|}
\hline Matriculation Year & Zip Code \\
\hline Graduation Year & RUCA Code \\
\hline MD Granted Date & Rural/Urban Area \\
\hline Full Name & MUC (Medically Underserved Community) \\
\hline PGY1 Specialty & Board Certification \\
\hline PGY1 Institution & Matched in Categorical Surgery \\
\hline PGY1 City & Matched in Preliminary Surgery \\
\hline PGY1 State & Practiced General Surgery \\
\hline Training State to Practice State & Practiced General Surgery in Alabama \\
\hline Practicing Specialty & Practiced General Surgery in Rural Alabama \\
\hline Subspecialty & Practiced General Surgery in Rural U.S. \\
\hline Rural Medical Scholars Program & Matched in Subspecialty Surgery \\
\hline Primary Care/Other & Matched in Family Medicine \\
\hline Practicing Matched Specialty & Practiced Family Medicine in Alabama \\
\hline Practice Location & Practiced Family Medicine in Rural Alabama \\
\hline Practice State & Practice Primary Care \\
\hline Address & Practiced Primary Care in Alabama \\
\hline Contact Telephone & Practiced Primary Care in Rural Alabama \\
\hline Stayed in Alabama/Left Alabama & \\
\hline
\end{tabular}

Table 2. Production of Obstetrician/Gynecologists in the UASOM System, 1974 to 2015

\begin{tabular}{|l|c|c|c|}
\hline CAMPUS $^{\mathbf{1}}$ & BIRMINGHAM & TUSCALOOSA & HUNTSVILLE \\
\hline Total Students & 4498 & 850 & 923 \\
\hline Matched in OB/GYN & 332 & 51 & 52 \\
\hline Matched Percentage & $7.3 \%$ & $6.0 \%$ & $5.6 \%$ \\
\hline \# Still in Residency & 28 & 6 & 8 \\
\hline Changed to OB/GYN & 22 & 4 & 4 \\
\hline Changed to Other or Unknown Specialty & 18 & 1 & 3 \\
\hline Practiced OB/GYN & 254 & 40 & 42 \\
\hline Percentage Practicing OB/GYN & $83.5 \%$ & $88.9 \%$ & 30 \\
\hline Practiced Subspecialties & 54 & 8 & 30 \\
\hline
\end{tabular}

${ }^{1}$ The Montgomery campus opened in 2014 and that data was not included in this study 
specialties for a variety of reasons including lifestyle, work hours, litigation concerns and salary. Some medical students who enjoyed OB/ GYN and matched into other specialties may ultimately practice OB/ GYN. To meet the needs of the future, medicine must maximize the use of and encourage the production of obstetrics providers.

\section{References}

1. Alabama Vital Events, 1986-2014, Alabama Department of Public Health, Center for Health Statistics, Montgomery, AL

2. Powell J, Skinner CA, Lavender PD, Avery DM, Leeper JD (2018) Obstetric Care by Family Physicians and Infant Mortality in Rural Alabama. J Am Bd Fam Med 31: 542549. [Crossref]

3. Avery DM, McDonald JT (2014) The Declining Number of Family Physicians Practicing Obstetrics: Reasons, Recommendations and Considerations. Am J Clin Med 10: 70-78.
4. Rayburn WF, Klagholz JC, Murray-Krezan C, Dowell LE, Strunk AL (2012) Distribution of American College of Obstetricians and Gynecologists Fellows and Junior Fellows in Practice in the United States. Obstet Gynecol 119: 1017-1022. [Crossref]

5. Loy CS, Wharton RB, Dunbar JA (2017) Workforce Trends in Specialist and GP Obstetrics Practice in Victoria. Med J of Aust 186: 26-30. [Crossref]

6. Fisher TK. Maternity Care Work Force Analysis CPM Symposium. March 18, 2012 Adapted from Rayburn WF: The Obstetrician/Gynecologist Workforce in the United States: Facts and Implications.

7. Rayburn WF. The Obstetrician/Gynecologist Workforce in the United States-Facts, Figures and Implications, American College of Obstetricians and Gynecologists, 2017.

8. Dall TM, Chakrabarti R, Storm MV, Elwell EC, Rayburn WF (2013) Estimated Demand for Women's Health Services by 2020. J Women's Health 22: 643-648. [Crossref]

9. 2014 ACOG Workforce Fact Sheet: Alabama. American Congress of Obstetricians and Gynecologists, 2014

Copyright: $\odot 2018$ Avery DM. This is an open-access article distributed under the terms of the Creative Commons Attribution License, which permits unrestricted use, distribution, and reproduction in any medium, provided the original author and source are credited. 